\title{
Geographical variations of negative cloud-to-ground lightning parameters: a review
}

\author{
Osmar Pinto Jr., Iara R. C. A. Pinto and Kleber P. Naccarato \\ Atmospheric Electricity Group \\ Brazilian National Institute for Space Research - INPE \\ São Paulo, Brazil \\ E-mail: osmar@dge.inpe.br
}

\begin{abstract}
This paper reviews the information available on the dependence of negative cloud-to-ground (CG) lightning characteristics on geographical location. From the information available in the literature at the present time, there is no conclusive evidence of a significant dependence of negative CG lightning parameters on geographical location, except maybe for current intensity (first and subsequent stroke peak current and average continuing current), for which a small (less than $50 \%$ variation) dependence may exists, and multiplicity. Nevertheless, it cannot rule out that the differences in current measurements are due to reasons other than "geographical location".
\end{abstract}

Keywords-negative cloud-to-ground;geographical location; lightning characteristics

\section{INTRODUCTION}

A possible dependence of lightning parameters on geographical location has been pointed out for many years, in particular for the peak current of first strokes in negative cloudto-ground (CG) flashes [1, 2]. However, no conclusive evidences has been reported until now, in part due to the difficulties to obtain statistically significant data sample and to eliminate the effects caused by changes in the instrumentation and data analysis usually present in the observations made at different locations.

In this paper it will be discussed the dependence of negative CG lightning parameters on the geographical location, in particular the return stroke peak current and front duration (for both first and subsequent strokes), flash multiplicity, interstroke interval, number of channels per flash and continuing current (intensity and duration). For other lightning parameters for negative CG flashes, such as M-components and return-stroke speed, no sufficient information is available for a reliable analysis and, in consequence, it will not be discussed here.

There is also no sufficient information for a reliable analysis of the dependence of positive CG lightning parameters on geographical location. It is worth mentioning that, in spite of this fact, there are many evidences suggesting a dependence of the parameters of positive CG flashes on the type of the thunderstorms and season, including observations suggesting different current waveforms of positive flashes in the coastal area of the Sea of Japan at different seasons (see [3] for a review). Assuming that the prevalent type of thunderstorms may be different in different locations and seasons, the above dependence implies a dependence on the geographical location.

Although it is well known that flash density [3, 4] and polarity $[3,5]$ have dramatic variations with geographical location and season, it has been controversy if other lightning parameters also have significant similar variations. Such controversy, which has been discussed on the literature for many years, is a direct result of the complexity of the physical process responsible for the various observed lightning features and the inherent limitations of lightning detection techniques. Before attributing any variation of lightning parameters to regional or meteorological peculiarities, one should make certain that measuring and data processing techniques used in different locations possess similar capabilities so as to allow a meaningful comparison of the different measurements [6]. Although any technique has some limitations, for a given lightning parameter these limitations could be more or less important. For this reason, one should be very carefully when comparing different observations using different techniques. Other important aspect is related to the level of statistical significance of a given variation, sometimes not completely addressed by the data analysis [3]. Also, it is very important in any comparison of $\mathrm{CG}$ lightning parameters to exclude any upward and intracloud lightning from the analysis. In some cases and for some techniques, this task could be very difficult if not impossible.

From the physical point of view, any geographical variation in lightning parameters related to latitude, topography or other surface feature, continentality or a seasonal variation in temperature, humidity, general atmospheric circulation or other meteorological feature, should be in fact related to variations in the thunderstorm electrical structure due to these features. In consequence, in order to fully understand a given variation in a lightning parameter, we need to understand how this variation could be explained in terms of variations in thunderstorm structure. The complexity to understand these processes, however, makes in some cases very difficult to fully understand the causes of the variations. In consequence, a 
detailed statistical analysis and a rigorous technical evaluation is recommended to avoid obtain spurious results.

Due to the difficulties mentioned above, the results presented in this paper will be divided in three sections describing variations in: return stroke peak current and front duration; flash multiplicity, interstroke interval and number of channels per flash; and continuing current average intensity and duration. All information concerns CG negative flashes. No attempt is done to make a comprehensive review of the literature. Instead, emphasis is done to compare recent observations using a same technique in different regions or observations considering large sample sizes using similar techniques. A comprehensive review of past results can be found elsewhere [3, 7].

A summary of the recent information available in the literature will be presented indicating if there is or there is no evidence of a dependence of negative CG lightning parameters on geographical location for the different parameters mentioned previously. Any exceptions that could exist to get a general picture will be mentioned and discussed.

\section{Return Stroke PEAK CURRENT AND Front DURATION}

Direct current observations by short instrumented towers provide the most precise measurements of first and subsequent return stroke peak current and front duration. However, in many studies the number of events is small, so that the statistical significance is limited. In addition, small changes in the instrumentation or data analysis from one to other study may lead to differences in the measured peak currents and front durations. Also, the topography causes differences in the effective height of the towers that may lead to differences in the measured peak currents and front durations.

The larger data sets of first and subsequent return stoke current waveforms observed in short instrumented towers were obtained in Mont San Salvatore, Switzerland - 101 negative CG flashes [8, 9], in Foligno and Monte Orsa, Italy - 42 negative flashes [10] and in the Cachimbo Mountain, Brazil 31 negative $C G$ flashes [11]. In addition, a large data set of current waveforms (120 negative CG flashes - only first strokes) was measured in 60 transmission line towers in Japan by Takami and Okabe [12]. Although obtained in different towers, under different conditions, the results of the in Japan is included in the analysis considering its large sample size. Others studies using short towers had measured current waveforms of negative CG flashes, but the sample size are very small and for this reason their results will be not discussed here.

While the towers in Switzerland and Italy are no more operational, the Brazilian tower operated from 1985 to 1998 (13 years), returning to operation in 2007 when it was updated with a new instrumentation. Since the sample size after 2007 is too small, the analysis here will be concentrated in the period before the update. Nevertheless, the influence of the results after the update on the previous results, as reported by Visacro et al. [13], will be mentioned in the text.

Table 1 shows the median peak current calculated from the observations cited above.

TABLE 1. Median values of first stroke peak current calculated from observations in different instrumented towers.

$\begin{array}{lcc}\text { Location } & \text { Peak Current (kA) } & \text { Number of Events } \\ \text { Switzerland } & 30 & 101 \\ \text { Brazil* } & 45 & 31 \\ \text { Japan } & 29 & 120 \\ \text { Italy } & 33 & 42\end{array}$

*The value in Brazil does not change if the observations after 2007 are included [13].

Some interesting aspects related to these observations are:

1. When the observations in Switzerland and Brazil are sorted by season, the same median values are obtained in Brazil when comparing the summer observations with those in the other seasons (although the number of flashes out of summer -8 - is low to obtain a significant mean value), while in Switzerland the median value in the summer $(37 \mathrm{kA})$ is larger than in the other seasons (30 kA) by $20 \%$, suggesting a possible seasonal dependence.

2. No peak current values below $20 \mathrm{kA}$ were observed in the period from 1985 to 1998 in Brazil (the same is not true after 2007 [13]). This fact partially explains the larger value for Brazil shown in Table 1.

3. The measurements in Japan are restricted to peak currents above $9 \mathrm{kA}$.

4. In all observations a possible contamination by upward flashes cannot be totally disregarded, mainly in Japan, although it is unlike judging from the measured current waveforms.

On the other hand, first-stroke peak current estimates obtained by lightning location systems (LLS) are subjected to large uncertainties. However, even considering these large uncertainties, the relative annual variation of the peak current for a given LLS can give an idea of the possible dependence of this parameter on different meteorological conditions predominant at different seasons. Pinto et al. [14] have studied the annual variation of negative flashes observed by different LLS, in particular the NLDN in the United States and the RINDAT network in Southeastern Brazil. They found that the annual variations for both networks are lower than $10 \%$ (Figure 1).

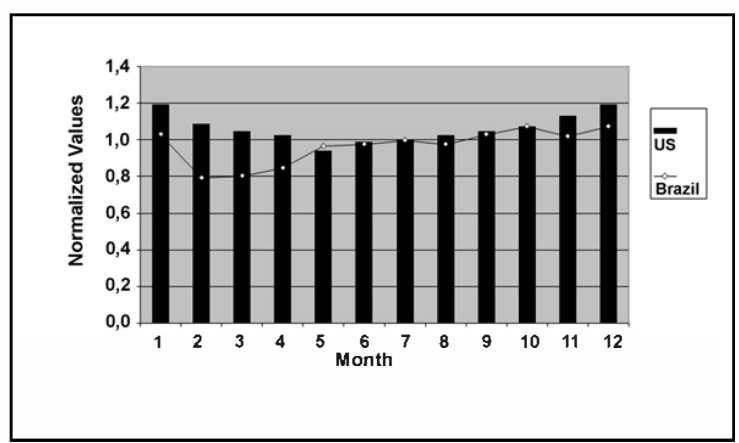


Figure 1. Normalized mean monthly distribution of the negative first-stroke peak current observed by RINDAT in Southeastern Brazil from 1998 to 2005 and by NLDN in United States from 1989 to 1999.

Recently, Saraiva [15] have suggested based on a preliminary analysis that the peak current of negative CG flashes increases by about $10 \%$ as the height of the $35 \mathrm{dBZ}$ echo increases from 8 to $15 \mathrm{~km}$. However, the results need confirmation considering a larger sample of data.

First return stroke front duration can also be measured with precision only by direct current observations in instrumented towers. Table 2 shows the median values of front duration obtained in Switzerland [9], Brazil [11], Japan [12] and Italy [10], calculated as the time between the $10 \%$ and $90 \%$ values of the amplitude of the first peak in the current wave front (T10). The differences are lower or of the order of one standard deviation suggesting that no changes exist in different locations.

TABLE 2. Median values of front duration (T-10) for first strokes calculated from observations in different instrumented towers.

Location

Front Duration ( $\mu$ s) Number of Events

$\begin{array}{lcr}\text { Switzerland } & 4.4 & 101 \\ \text { Brazil* } & 5.6 & 31 \\ \text { Japan } & 4.8 & 120 \\ \text { Italy } & 7.2 & 42\end{array}$

*The value in Brazil changes to 5.1 if the observations after 2007 are included [13]

Table 3 shows median values of peak current and front duration (T-10) for subsequent return strokes calculated from observations in Switzerland, Brazil and Italy. Again, the differences are higher for peak current, while the differences for front duration are lower and of the order of one standard deviation.

TABLE 3. Median values of peak current and front duration (T-10) for subsequent return strokes calculated from observations in different instrumented towers.

Location Peak Current (kA) Front Duration ( $\mu$ s) Number of Events

$\begin{array}{lccc}\text { Switzerland } & 12.0 & 0.9 & 135 \\ \text { Brazil* }^{*} & 16.3 & 0.7 & 59 \\ \text { Italy } & 18.0 & 0.9 & 33\end{array}$

*The value in Brazil changes respectively to 17.5 and 0.6 if the observations after 2007 are included [13].

The above considerations suggest that small variations in the first and subsequent return stroke peak current may exist for different geographical locations. The reason for the variations could be changes in the prevalent type of thunderstorms in these locations. However, it cannot be rule out the possibility that a significant part of the observed variations resulting from variations in the instrumentation or data analysis. In contrast, the observations of front duration seem to suggest no dependence on geographical location.

\section{FLASH MULTIPLICITY, INTERSTROKE INTERVAL AND NuMBER OF CHANNELS PER FLASH}

The most precise technique to record flash multiplicity, interstroke Interval and number of channels per flash is high speed cameras in conjunction with microsecond-scale electric and magnetic field records. The flash multiplicity of negative flashes was recently studied by Saraiva et al. [16] in Arizona (United States) and São Paulo (Brazil) using a same high speed camera. Figure 2 compares the number of strokes per flash in Arizona and São Paulo. Note that the percentage of flashes with a given number of strokes is very similar in both regions. The figure also shows that the most common value of the multiplicity was 2 in both locations. The percentage of singlestroke flashes is also almost the same in both regions and approximately $20 \%$.

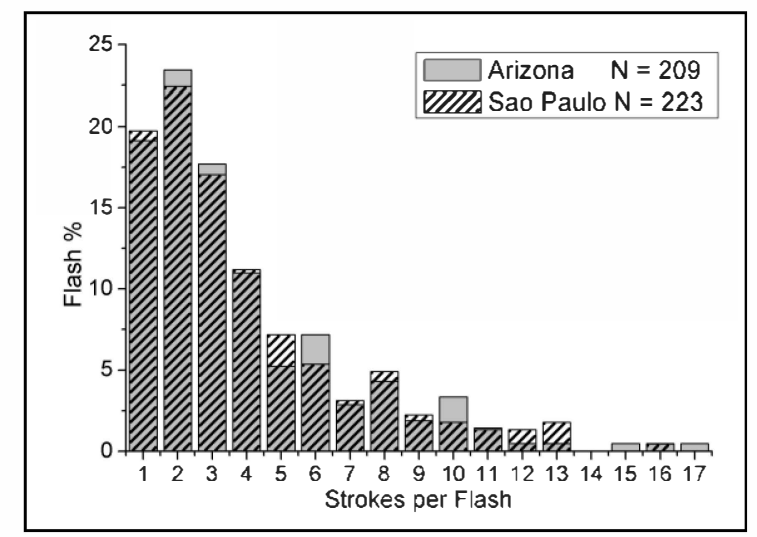

Figure 2. Percentage of flashes versus the number of strokes per flash (or multiplicity) observed in Arizona and São Paulo.

Another technique capable to obtain accurate values of multiplicity is electric field measurements. Observations using this technique have been done in Sri Lanka by Cooray and Jayaratne [17], in Sweden by Cooray and Perez [18] and in Florida by Rakov and Uman [19, 20] and Thottappillil et al. [21]. For a review of these and other past observations see Ballarotti et al. [22]. All results suggest a same multiplicity in different regions.

However, more recently, Saraiva [15] have showed that when the multiplicity data are sorted by different storm types in the observations in Arizona and São Paulo in [16], a clear 
storm-to-storm lightning parameter variation is observed in both places, in agreement with past observations in Russia [23]. Data from lightning location system observations in Austria [24] and United States [5, 25, 26] and from a slow rotating streak-camera array in United States [27] also suggest significant variation of this parameter for different thunderstorms. Saraiva [15] suggested that the multiplicity of negative flashes is correlated with the horizontal extent of the main negative charge region within the parent thunderstorm as estimated by the area enclosed by the $35 \mathrm{dBZ}$ reflectivity contours at the level of the $-10{ }^{\circ} \mathrm{C}$ isotherm as observed by radar images. In consequence, it is possible that different regions may present different long-term flash multiplicity if they have different occurrence combination of different storm types. However, more studies are needed in order to confirm this hypothesis.

Observations of interstroke interval for negative flashes in different regions using an accurate technique have been published recently $[15,16]$. The measurements were done by a high speed camera including 1210 interstroke intervals observed in Arizona and São Paulo. The values ranged from a few $\mathrm{ms}$ to $782 \mathrm{~ms}$. The median values $(60 \mathrm{~ms})$ was essentially the same in both locations. This value is also the same that observed by Schulz et al. [28] in Austria in a 10-year study using data from a high detection efficiency lightning location system. Many other authors have reported median values of interstroke intervals around $60 \mathrm{~ms}$ [e.g., 6, 17, 29, 30]. Figure 3 shows a comparison of the frequency of occurrence of interstroke intervals in Arizona and São Paulo.

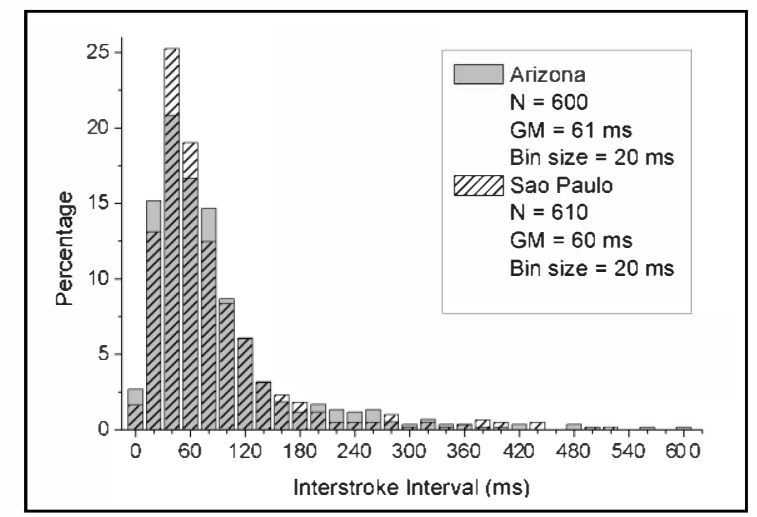

Figure 3. Distributions of interstroke intervals in Arizona and São Paulo.

Another parameter investigated for changes in different geographical locations is the average number of ground contacts per flash or ground terminations. Saraiva [15] found that about half of the 344 flashes observed in Arizona and São Paulo exhibited one or more ground terminations. Figure 4 shows how the numbers of ground contacts are distributed and again the result is very similar between Arizona and São Paulo. The average number of ground contacts in both locations is 1.7 in both locations in agreement with previous observations reported for United States obtained by standard cameras [6].

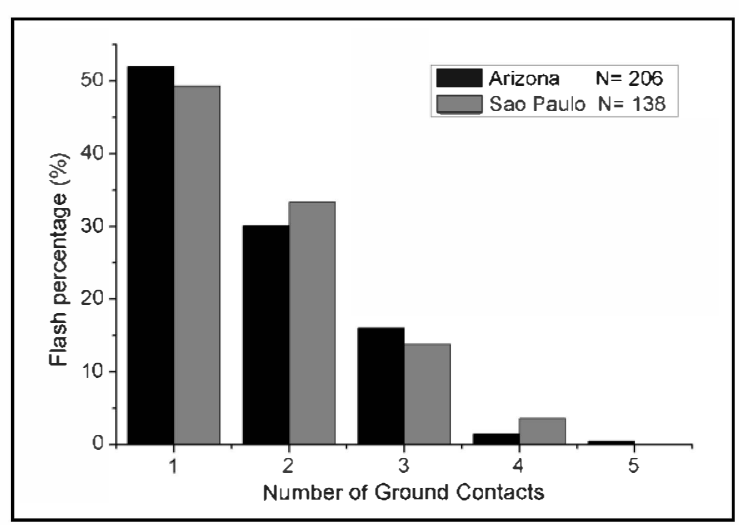

Figure 4. Percentage of flashes that produce a given number of ground contacts in Arizona and São Paulo.

\section{CONTINUING CURRENT INTENSITY AND DURATION}

Only three studies [29, 31, 32] have investigated the average intensity and duration of continuing currents (CC) of negative flashes using a large data set obtained from electric field observations by slow E-field antennas. The observations were done in Florida [29], New Mexico [30] and São Paulo, Brazil [32] and are compared in Figure 6, where all data were corrected by deconvolution.

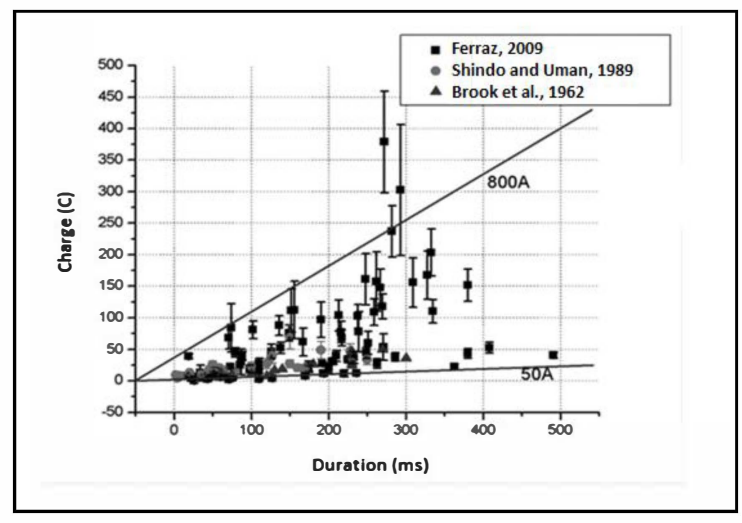

Figure 6. Diagram of charge versus duration for negative $\mathrm{CC}$ indicating the scattering in the average current values.

The results suggest that the $\mathrm{CC}$ average intensity in Brazil is larger than in United States, although more data at other locations are necessary before a definitive conclusion.

Figures 7 and 8 show recent results about the duration of the CC obtained in Arizona and São Paulo [16], inferred from 
the duration of the channel luminosity following the return stroke obtained by high speed camera observations using a same camera. Figure 7 shows the distributions of duration for short CC. The differences are likely due to the small sample size. In turn, Figure 8 shows the distribution of the long CCs and again no significant variations are observed.

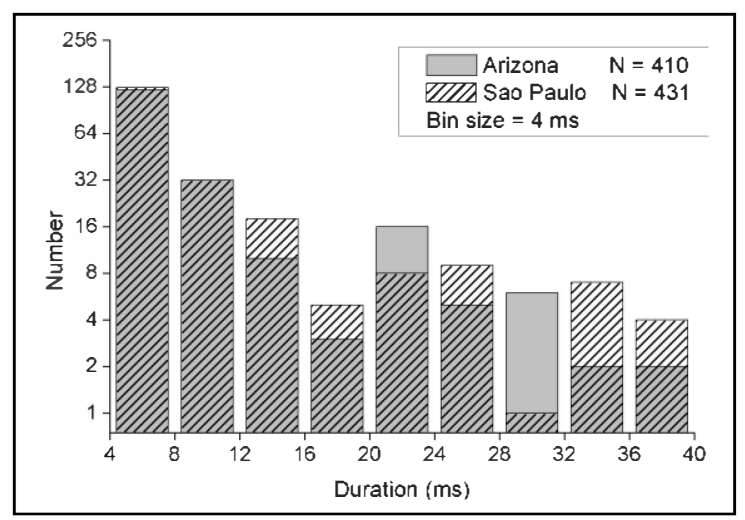

Figure 7. Distribution of short continuing current durations in Arizona and Brazil. The distributions are very similar.

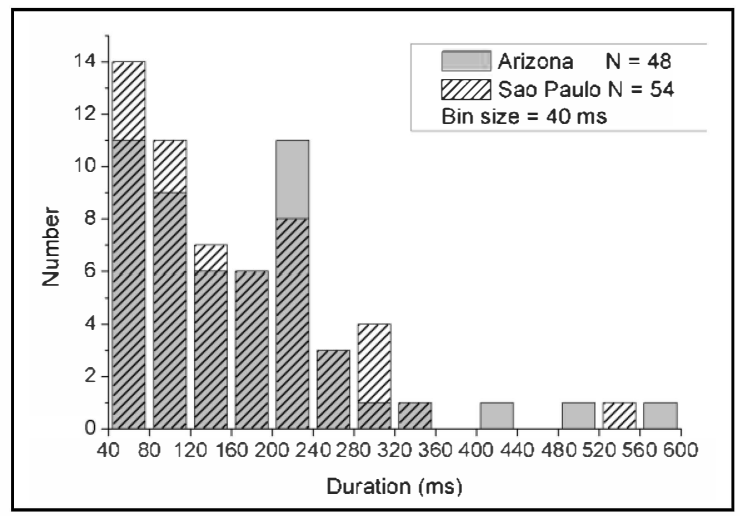

Figure 8. Distribution of long continuing currents in Arizona and São Paulo. There are no significant differences between the two regions.

In summary, the available data using the same technique in different regions do not support any dependence of the $\mathrm{CC}$ duration on geographical location.

\section{SUMMARY}

From the information available in the literature at the present time, there is no evidence of a dependence of negative CG lightning parameters on geographical location, except maybe for current intensity (first and subsequent stroke peak current and average continuing current), for which a lower dependence may be expected (variations by less than $50 \%$ ) and multiplicity. Nevertheless, it cannot rule out that the differences in current measurements are due to reasons other than "geographical location".
Obviously, exceptions could exist such as the long duration current waveforms reported by Miyake et al. [33] in the winter time in the coastal area of the Sea of Japan. Further studies are necessary, however, to clarify if the observed exceptions represent actual variations in flash characteristics with the geographical location or represent extreme values of a common distribution.

\section{ACKNOWLEDGMENT}

The authors would like to thank V. A. Rakov for discussions and comments on the manuscript.

\section{REFERENCES}

[1] Anderson, R. B. and Eriksson, A. J. "Lightning parameters for engineering application, Electra, vol. 69, pp. 65-102, 1980.

[2] Pinto Jr., O. et al., "Are equatorial negative lightning flashes more intense than those at higher latitudes?", J. Atmos. Solar-Terr. Phys., vol. 59, pp. 1881-1883, 1997.

[3] Rakov, V. A., and Uman, M. A. "Lightning: Physics and Effects", Cambridge University Press, Cambridge, 687 p., 2003.

[4] Pinto, O., Jr., Pinto, I. R. C. A., and Naccarato, K. P., "Maximum cloudto-ground lightning flash densities observed by lightning location systems in the tropical region: A review", Atmos. Res., vol. 84, pp. 189200, 2007.

[5] Orviille, R. E., Huffines, G.R., Burrows, W.R., and Cummins, K.L., "The North American Lightning Detection Network (NALDN) Analysis of flash data: 2001-2009", Mon. Wea. Rev., vol. 139, pp. 1305-1322, 2011

[6] Rakov, V.A., Uman, M.A., and Thottappillil, R., "Review of lightning properties from electric field and TV observation", J. Geophys. Res., vol. 99, pp. 10,745-10,750, 1994.

[7] Diendorfer, G. et al., "Cloud-to-ground lightning parameters derived from lightning detection systems", CIGRE report, 2008.

[8] Berger, K., "Novel Observations on Lightning Discharges: Results of Research on Mount San Salvatore", J. Franklin Institute, vol. 283, pp. 478-525, 1967.

[9] Berger, K., Anderson, R. B., and Kröninger, H., "Parameters of Lightning Flashes, Electra", vol. 41, pp. 23-37, 1975.

[10] Garbagnati, E. and Lo Piparo, G. B., "Parameter von Blitzstromen, Elektrotechnische Zeitschrift”, vol. 103, pp. 61-65, 1982 (in German).

[11] Visacro, S., Soares Jr., A., Schroeder, M. A. O., Cherchiglia, L. C. L., and Sousa, V. J., "Statistical analysis of lightning current parameters: Measurements at Morro do Cachimbo Station", J. Geophys. Res., vol. 109, doi:10.1029/2003JD003662, 2004.

[12] Takami, J. and Okabe, S., "Observational results of lightning current on transmission towers", IEEE Trans. Pow. Del., vol. 22, pp. 547-556, 2007.

[13] Visacro, S., Mesquita, C. R., Batista, M. P. P., Araújo, L. S. and Teixeira, A. M. N., "Updating the statistics of lightning currents measured at Morro do Cachimbo Station", Proceedings of the 30th International Conference on Lightning Protection - ICLP 2010, Cagliari, Italy, September, 2010.

[14] Pinto Jr., O., Naccarato, K.P., Pinto, I.R.C.A., Fernandes, W.A. and Pinto Neto, O., "Monthly distribution of cloud-to-ground lightning flashes as observed by lightning location systems", Geophys. Res. Lett, vol. 33, doi:10.1029/2006GL026081, 2006.

[15] Saraiva, A. C. V., "Study of the factors that determines the characteristics of cloud-to-ground negative flashes", $\mathrm{PhD}$ Thesis, Brazilian Institute of Space Research (INPE), 162 p., 2010 (in Portuguese). 
[16] Saraiva, A. C. V. et al., "Comparative Study of Negative Cloud-toGround Lightning Characteristics in Sao Paulo (Brazil) and Arizona (USA) using High-speed Video Observations", J. Geophys. Res., vol. 115, doi:10.1029/2009JD012604, 2010.

[17] Cooray, V. and Jayaratne, K. P. S. C., "Characteristics of lightning flashes observed in Sri Lanka in the tropics", J. Geophys. Res., vol. 99, pp. 21,051-21,056, 1994.

[18] Cooray, V. and Pérez, H., "Some Features of Lightning Flashes Observed in Sweden", J. Geophys. Res., vol. 99, pp. 10,683-10,688, 1994.

[19] Rakov, V. A. and Uman, M. A., "Long continuing current in negative lightning ground flashes", J. Geophys. Res., vol. 95, pp. 5455-5470, 1990.

[20] Rakov, V. A. and Uman, M. A. "Some Properties of Negative Cloud-toGround Lightning", in Proc. 20th Int. Conf. on Lightning Protection, Interlaken, Switzerland, Swiss Electrotechnical Association, 6.4/1-6.4/4, 1990.

[21] Thottappillil, R. et al., "Lightning subsequent stroke electric field peak greater than the first stroke peak and multiple ground terminations", J. Geophys. Res., vol. 97, pp. 7503-7509, 1992.

[22] Ballarotti, M. G., Saba, M. M. F., Pinto Jr., O., and Schulz, W., "Frequency Distribution of Some Parameters of Negative Downward Lightning Flashes Based on Accurate-Stroke-Count Studies", J. Geophys. Res., 2012 (in press).

[23] Rakov, V. A. and Dulzon, A. "Study of some features of frontal and convective thunderstorms", Meteor. Hidrol., vol. 9, pp. 59-63, 1986.

[24] Diendorfer, G., Schulz, W., and Rakov, V. A., "Lightning Characteristics Based on Data from the Austrian Lightning Locating
System", IEEE Transactions on Electromagnetic Compatibility, vol. 40, pp. 23-32, 1998.

[25] Orville, R.E., Huffines, G.R., Burrows, W.R., Holle, R.L., and Cummins, K.L., "The North American Lightning Detection Network (NALDN) - First Results: 1998-2000", Mon. Wea. Rev., vol. 130, pp. 2098-2109, 2002.

[26] Rakov, V. A. and Huffines, G. R., "Return-Stroke Multiplicity of Negative Cloud-to-Ground Lightning Flashes", J. Applied Meteor., vol. 42 , pp. 1,455-1,462, 2003

[27] Kitterman, C. G., "Characteristics of lightning from frontal system thunderstorms", J. Geophys. Res., vol. 85, pp. 5503-5505, 1980.

[28] Schulz, W., Cummins, K., Diendorfer, G., and Dorninger, M., "Cloudto-ground lightning in Austria: A 10-year study using data from a lightning location system", J. Geophys. Res., vol. 110, pp. 910-917, 2005.

[29] Shindo T., and Uman, M. A., "Continuing current in negative cloud-toground lightning”, J. Geophys. Res., vol. 94, pp. 5,189-5,198, 1989.

[30] Saba, M. M. F., Ballarotti, M. G., and Pinto Jr., O., "Negative cloud-toground lightning properties from high-speed video observations", J. Geophys. Res., vol. 111, D03101, doi: 10.1029/2005JD006415, 2006.

[31] Brook, M., Kitagawa, N., and Workman, E. J., "Quantitative study of strokes and continuing currents in lightning discharges to ground", J. Geophys. Res., vol. 67, pp. 649-659, 1962.

[32] Ferraz, E. C., "Continuing current measurements of negative flashes in Brazil", PhD Thesis, Brazilian Institute of Space Research (INPE), 133 p., 2009 (in Portuguese).

[33] Miyake, K., Suzuki, T., and Shinjou, K., "Characteristics of winter lightning current on Japan Sea coast", IEEE Trans. Pow. Del., vol. 7, pp. 1450-1456, 1992. 